\title{
The Medical Journal of Australia after 100 years
}

For a thousand years in thy sight are but as yesterday when it is past, and as a watch in the night.

Psalm 90: 4

W hen the first issue of the Medical Journal of Australia was published in Sydney on 4 July 1914, the editor Henry William Armit wrote:

[The Journal's] functions are clearly defined. It has to record the progress of scientific medicine, and to assist in rendering the practice of medicine in all its branches of the greatest benefit to the people of Australia ... It is, therefore, to be hoped that the members of the profession will make free use of the Journal in matters of policy.

These values have underpinned the goals of the Journal since. A parade of 16 editors, like the regenerations of Doctor Who, have served to guide the Journal through time and space. They have led the interplay of personality and human relations among the dramatis personae - the editorial team with its passions and foibles, the medical profession and its organisations, a host of ambitious contributors, the readers and the advertisers. Throughout, first the British then the Australian Medical Association has remained a steadfast parent, occasionally scolding but imperturbably loyal and generous in its support and tolerance, and proud of its independent progeny.

Are we being presumptuous in celebrating 100 years? A hundred years can feel either long (if you are a human) or short (if you are a deity or a dinosaur), and time is surprisingly malleable. Einstein's theories were stimulated by his observations of the elasticity of time when, while working in the Swiss patent office, he wrestled in 1905 with how to synchronise clocks across European time zones (Galison P. Einstein's clocks, Poincaré's maps. New York: WW Norton and Co, 2004). The concept of time as a straight line — alpha (before) to omega (after) — is not universal, as shown by its different conceptions among the world's languages. The notion that time may be circular and that events recur was a dark preoccupation throughout Nietzsche's life (Hatab LJ. Nietzsche's life sentence: coming to terms with eternal recurrence. New York: Routledge, 2005).

Throughout its century, the Journal has appeared regularly despite wars and economic depression. The Journal's birth year, 1914, was not great for humans. An unpredicted world war began in August and by its end in 1918 had wrought a catastrophe like that caused by the meteor or volcano that ended the era of the dinosaurs. Sixteen million deaths of combatants and civilians were followed by around 50 million more from the larger scourge of H1N1 influenza in 1918.

Since 1914, the Journal has benefited immensely from dedication, idealism, immense effort and deep altruism from many thousands of contributors and many times that number of readers.
Reassuringly, the Journal is still something of an anachronism, a quaint symbol of old-style values, a periodical (30000 copies per issue) that is a pleasure to browse in this day of net-surfing and smartphones. Its commitment to science; its passion to support the medical profession in providing the best possible information for use in clinical practice; and a belief in education and lifelong learning are all values it has secured across the century.

The Journal has, nevertheless, kept pace with the changes refashioning all media, as massive linotype machines and printing presses have yielded to laptops and laser printers. The Journal has been fully online since 2002. We have a precious cousin in MJA InSight that encourages reader commentary and welcomes debate, and delivers news and material from the Journal and beyond to 44000 people via email each week. You can follow us through the rainforest of social media, retweeting us on Twitter, liking us on Facebook and connecting with us on LinkedIn and Google+.

Given the exponential rate of electronic evolution, Eric Schmidt, executive chairman of Google, claimed that humans now create as much information every 48 hours as we made from the dawn of civilisation to 2003 - that's five exabytes of data, or five billion gigabytes, in 2 days. Others judge his estimate, like his wealth, as excessive (http://readwrite.com/2011/02/07/are-we-really-creatingas-much). What is certain, however, is that the Journal's tasks of critical appraisal and communication have become ever more important in managing this avalanche of information, including that coming from the sciences.

How much the Journal remains bound to print as its primary medium is not clear. How a move away from print would affect the format of the Journal is important for the business. Furthermore, the increased accessibility and shareability of information, and the various ways it may be exploited, affect publishing practice. Constructs of confidentiality and privacy will evolve, potentially in unexpected ways, owing to increasing access to databases holding our personal information from sources as varied as checkout registers to electronic medical records. These developments will influence the ethics of medical publication in ways yet to be envisaged.

Two necessary actions stand out as we turn 100 and look to the future. First, we must reaffirm the original values on which the Journal was based. They have stood the test of time and changing circumstance and are likely to continue to do so. Second, we must balance our past mastery with a watchful, critical yet eager openness to the unbidden (Lancet 2007; 370: 310) and be ready to progress and change in ways that are consistent with the Journal's role and values.

Stephen Leeder Editor-in-Chief

mja@mja.com.au doi: 10.5694/mjal4.c0707 